\title{
Atravessando as bordas do círculo mágico: imersão, atenção e videogames
}

\section{Crossing the boundaries of the magic circle: immersion, attention and video games}

Emmanoel Ferreira ${ }^{1}$

Thiago Falcão ${ }^{2}$

Resumo Este trabalho propõe uma discussão sobre o círculo mágico, conceito bastante debatido nos últimos anos no âmbito dos jogos em geral, e em particular dos videogames. Através de um diálogo com autores dos game studies, como Johan Huizinga e Katie Salen e Eric Zimmerman, assim como com autores da psicologia cognitiva que discutem a questão da atenção, argumentamos que o círculo mágico, ao invés de separar ficção e realidade - conforme defendido por diversos autores - funciona como uma estrutura cognitiva de mediação, cuja existência ocorre de formas diferenciadas e gradativas, de acordo com a operação de processos imersivos e atencionais entre jogador e dispositivo tecnológico, neste caso o videogame.

Palavras-chave: Círculo Mágico; Imersão; Atenção; Videogames

Abstract This paper proposes a discussion about the concept of magic circle, which in the last years has been thoroughly debated within the context of games in general and video games in particular. Through a dialogue with authors of the game studies' field, such as Johan Huizinga and Katie Salen and Eric Zimmerman, as well as authors of cognitive psychology that discuss the issue of attention, we argue that the magic circle, instead of separating fiction and reality - as advocated by several authors - works as a cognitive structure of mediation, whose

\footnotetext{
${ }^{1}$ Universidade Federal Fluminense - UFF, Niterói, RJ, Brasil.

E-mail: emmanoferreira@midia.uff.br

${ }^{2}$ Universidade Federal Fluminense - UFF, Niterói, RJ, Brasil.

E-mail: falc4o@gmail.com
} 
74 ATRAVESSANDO AS BORDAS DO CÍRCULO MÁGICO

existence occurs in differentiated and gradual forms, according to immersive and attentional processes that work between player and technological device, in this case the video game.

Keywords: Magic Circle; Immersion; Attention; Video Games 


\section{Introdução}

Se desejamos entender os processos através dos quais se faz comunicação e se produzem culturas contemporâneas, precisamos reconhecer que os videogames abandonaram há muito o status de diversão adolescente para figurar em todo o espectro da cultura. Yee (2014) possui vários números para ilustrar este argumento. Mundo afora, milhares de designers e desenvolvedores se apropriam dos videogames com os mais diversos propósitos. Seu consumo segue a dinâmica da midiatização: é pervasivo e está em tudo que consumimos; desde os filmes que assistimos no cinema ao Jornal Nacional. A era de Zelda e de Mario passou - a era na qual tudo era diversão infantil. Caminhamos, neste momento, rumo a um panorama no qual os jogos eletrônicos podem ter um status de importância semelhante ao que o gamão e o xadrez tiveram durante o Iluminismo.

Naturalmente, naquele momento, mesmo estes jogos, possuidores de tamanha complexidade, estavam confinados ao status de lazer improdutivo, de subserviência ao homem moderno. A questão que se faz presente aqui é: hoje, podemos executar uma operação de purificação como esta? Debates sérios a respeito de onde os jogos eletrônicos encontram a arte vêm sendo travados continuamente, e mesmo o Museu de Arte Moderna de Nova Iorque (MoMA) decidiu que os primeiros jogos comercializados precisavam ser conservados.

Não obstante, jogamos em toda parte: em nossos celulares, em nossos perfis em redes sociais, aderimos a programas de pontos, comentamos em fóruns, jornais e revistas eletrônicas gamificados - transformados em jogo ou que guardam elementos do jogo.

Ainda assim, no Brasil, os estudos sobre videogames estão distribuídos de forma esparsa num espectro interdisciplinar que lhes priva do status que necessitam. Abordagens tecnicistas e abordagens filosóficas divergem umas das outras, quando o ponto crucial é que o jogo seja encarado como o híbrido que é - um produto que nasceu em meio à diversão adolescente, mas que chega à sua maior idade e começa - começa! - a desenvolver questionamentos acerca de sua ética e estética; a flertar com gêneros radicalmente diferentes daqueles que lá figuravam. 
Neste sentido, o intuito deste artigo é precisamente de ordem interdisciplinar: ele busca desenvolver um modelo de entendimento para a noção de "círculo mágico" (SALEN e ZIMMERMAN, 2003; HUIZINGA, 1938) que esteja atrelado às discussões do campo da comunicação. Sobretudo buscamos esta conexão prático-teórica ao problematizar processos cognitivos que estão ligados não apenas às questões epistemológicas do campo, mas principalmente à sua práxis - processos identificados no jornalismo, na publicidade, na interação e nas redes sociais. O artigo articula a discussão em torno da ideia de círculo mágico com as noções de imersão e atenção, apontando para um entendimento da relação entre indivíduo e jogo que dialoga de forma instrumental com as discussões acerca dos processos cognitivos da comunicação.

\section{Círculo mágico}

O caráter moderno nas obras clássicas do campo dos game studies confere à atividade analisada por estas - o jogo - um tom necessariamente dicotômico: Huizinga (1938) e Caillois (1958) não acreditam na possibilidade da conciliação entre uma atividade "não séria" e a vida útil; o ser humano adulto e responsável não joga, a não ser por uma corrupção da atividade (CAILLOIS, 1958). Já as crianças, estas são obrigadas a fazê-lo, porque é da criança jogar; uma característica que lhe é essencial e incontornável (HUIZINGA, 1938).

Não é incomum que encontremos este tipo de discurso na obra dos dois pensadores referenciados acima, mas é intrigante (e preocupante) o modo como este tipo de discurso ainda subsiste no trato que a imprensa contemporânea oferece às esferas do trabalho e da atividade lúdica - da "vida normal" e do jogo. Mesmo que em suas múltiplas representações - board games, videogames, RPGs - o jogo seja ubíquo, ainda pertence a ele a imagem de bobo, de pertencente ao mundo infantil.

Para Huizinga (1938) e Caillois (1958), a atividade do jogo consiste na criação de um suposto "outro" lugar espaço-tempo no qual a atividade lúdica se desenvolve. Huizinga, em seu Homo Ludens, chamou esta pararrealidade de círculo mágico, sobretudo ao ressaltar que a atividade 
lá desenvolvida ignoraria completamente o mundo exterior. Esportes são um ótimo exemplo desta ocorrência, uma vez que possuem linhas que delimitam o campo de ação no qual se dá tal atividade; mesmo o futebol jogado na rua, limitado pelas sarjetas das calçadas e no qual o gol é formado por sandálias previamente posicionadas, obedece a esta dinâmica.

Salen e Zimmerman (2003) publicaram seu tratado de desenvolvimento e análise dos processos constitutivos do jogo - desde seu suporte analógico, representado comumente por cartas e tabuleiros, até suas representações digitais, os jogos eletrônicos. Neste, os autores retornaram à noção de Huizinga, articulando-a de forma funcional. Assim a ideia de jogo como atividade foi associada à de círculo mágico.

Ainda que seja fundamentado em um dos mais clássicos tratados sobre a relação entre cultura e expressão lúdica, a noção desenvolvida por Salen e Zimmerman (2003) sofreu consideráveis críticas no decorrer dos últimos 10 anos. Estas, contudo, serviram mais para inflamar a discussão acerca das noções de espaço secundário, enquadramento ou momento sagrado do que para desconstruir a proposta daqueles autores. Neste sentido, devemos considerar a ideia de transposição entre realidades, sustentada por Salen e Zimmerman (2003), quando questionam as atitudes psicológicas requisitadas de um jogador quando este se encontra em vias de iniciar um jogo.

Tal ideia - se tomada de maneira ampla - pode ser considerada uma alusão ao já bastante ultrapassado entendimento da relação realidade-ciberespaço como uma dicotomia; relação que vem sendo posta em xeque pelas teorias da cibercultura já há algum tempo - e mais proeminentemente representada pela ideia de tethered self da psicóloga americana Turkle (2008). Somos conduzidos, então, ao seguinte questionamento: é válido discursar acerca de uma barreira entre realidades - ou entre realidade e jogo - que precisa ser rompida?

Talvez sim, se considerarmos videogames nos quais a essência narrativa se faz mais perceptiva que a estrutura de regras; jogos que apontam para a necessidade de se lidar com experiências sensitivas particulares, o que 
viria a pressupor certa absorção do jogador no jogo (MURRAY, 1997). O mesmo já não pode ser dito quando nos endereçamos a outras categorias de jogos contemporâneos, como pervasive games, alternate reality games (ARGs) e MMORPGs, que trabalham no sentido de efetivamente "borrar" as fronteiras entre a "vida normal" e o mundo ficcional.

Desse modo, a ideia principal não seria considerar o círculo mágico como algo que necessariamente encapsula o jogador, suprimindo-lhe o espaço-tempo cotidiano, projetando-o em uma zona alternativa. Em detrimento deste raciocínio, optamos por considerar a existência do círculo mágico - uma propriedade da estrutura do jogo - como um elemento mediador, que trabalha no sentido de facilitar o diálogo do jogador entre jogo e vida normal.

Esta mediação, por sua vez, pode se apresentar tanto de forma fluida - ao desenhar fronteiras que se mostrem borradas, no sentido de que não podem ser plenamente identificadas, que permitam que ficção e realidade se encontrem - quanto de forma mais sólida, fazendo realmente com que o usuário/jogador experimente um sentimento de deslocamento, de supressão espaço-temporal, através de um processo imersivo.

Assim, nossa proposição é a de que o círculo mágico não separa efetivamente o "mundo do jogo" da realidade cotidiana, mas, antes disso, se estabelece como princípio de mediação, auxiliando o jogador a lidar com diferentes lados de um mesmo universo - e não com dois universos. Esta proposição nos leva a um entendimento mais específico: embora possamos nos referir ao jogo como objeto - ou seja, como bem simbólico produzido e comercializado -, é necessário considerar nuances da interação entre jogo e indivíduo. A formação do espaço-tempo, que é inerente ao jogo como atividade, demanda a interação entre sujeito e objeto.

Daí a proposição de Juul (2008) de que o círculo mágico é formado não apenas pela estrutura de regras, mas também pelos jogadores que são convocados a manter funcionando a ilusão de mundo, em um contrato de experiência conjunta - as bordas do círculo mágico são, então, negociadas e definidas pelos jogadores. Ele se constitui, portanto, no momento em que o objeto jogo se torna a atividade jogo, e assim evocando a presença do interagente para que exista produção de significado, 
o círculo mágico pode ser entendido como uma estrutura de mediação à medida que ele não é um delimitador de espaços, ou um mecanismo de transporte para outra dimensão, mas sim o ponto de contato onde a "vida normal" (HUIZINGA, 1938) se encontra com o "outro lugar".

A estrutura do jogo, com suas sólidas regras e códigos de conduta, possui esta qualidade de indulgência explorada na analogia entre espaços consagrados e espaços de jogo. Esta qualidade aparece exatamente no modo como os jogadores exploram, se apropriam, se adaptam às regras. Essa adaptação varia especialmente de acordo com a essência do jogo numa partida de futebol entre dois times de cinco pessoas, por exemplo, não é adequado parar 10 jogadores para atender o celular ou para verificar a meteorologia; em um Alternate Reality Game (ARG), como a relação para com o tempo e o espaço é eminentemente diferente da relação experimentada num esporte como o futebol, as indulgências são aceitas.

De acordo, então, com o que foi discutido com relação ao conceito de círculo mágico, podemos perceber que a mediação ocorre em duas dimensões distintas: a primeira delas diz respeito ao jogo enquanto objeto - bem simbólico construído e oferecido para consumo - e se dirige aos princípios técnicos envolvidos em sua criação: sua estrutura de regras e sua estrutura narrativa, que são os elementos que condensam toda a essência de tal dimensão; a segunda dimensão diz respeito ao modo como o jogo se apresenta no momento em que ele é jogado - ao jogo enquanto atividade; no momento em que ele adquire jogadores e, assim, estes iniciam os processos de apropriação e de adaptação comuns à relação entre homens e objetos. A essas duas dimensões do jogo - dimensões que são compositoras do entendimento do lugar consagrado e, portanto, do entendimento do círculo mágico - daremos maior atenção no próximo tópico.

\section{Elementos de composição da lógica do jogo}

A estrutura do jogo se dá em dois eixos, nos quais o primeiro (i) vai se debruçar sobre seus aspectos constitutivos: regras, que compõem a lógica do jogo, e ficção - na figura de mundos narrativos, diegese -, apoiada 
sobre aquelas. O segundo eixo (ii) trata do aspecto eminentemente social do jogo - do modo como os jogadores se apropriam e se adaptam ao que é oferecido pelo primeiro eixo. O entendimento do jogo por esses dois viéses é uma consequência direta da definição de jogo elaborada por Juul (2005). O autor garante, com sua divisão, uma maior qualidade de diferenciação aos estudos em jogos (estudos que podem estar centrados no sistema), que tratam do jogo enquanto objeto - ou em sua relação para com a sociedade e o mundo - tratando do jogo enquanto atividade. Nesta discussão, nos debruçaremos sobre o primeiro eixo, focalizando como os processos de imersão experimentados pelos jogadores podem assumir aspectos que estão voltados às vezes para as regras, às vezes para a narrativa.

\section{0 jogo como objeto: regras e ficção}

Proveniente do trabalho de Juul (2005), o entendimento dos jogos como sendo compostos por regras e ficção é fruto de uma discussão que remonta ao final da década de 1990, quando Aarseth (1997) publicou seu tratado sobre o aspecto sistemático e interativo de certos tipos de texto cibertextos, para o autor - e Murray (1997) publicou seu tratado sobre o aspecto dramático dos novos aspectos da mídia. Os dois tratados, apesar de não serem os únicos, são os mais expressivos e, portanto, os mais citados quando da defesa dos seus respectivos eixos: o da ludologia, no caso da obra de Aarseth (1997), e o da narratologia, no caso de Murray (1997).

Alguns autores enxergam videogames como uma nova forma - uma expansão - da narrativa tradicional. O problema em se analisar os videogames exclusivamente a partir de tal argumento é que falta um elemento muito simples e de importância-chave no processo da pesquisa: levar em conta que os videogames são, afinal, jogos. O elemento lúdico presente - tanto a presença da perspectiva agonística quanto a simples estrutura de regras, que clamam por interação - são características que não estão presentes em outras mídias de entretenimento - como o cinema ou a televisão. Além disso, as narrativas construídas através do computador guardam diferenças cruciais em relação a suas contrapartidas midiáticas: elas "tendem mais para a forma mais aberta do jogo (...) do que para a 
sequência irreversível de acontecimentos, que marca a experiência narrativa mais convencionalmente conhecida na literatura e no cinema" (MACHADO, 2002).

A forma aberta de que Machado fala refere-se precisamente ao fato que foi citado anteriormente: a interação, a participação, não é uma opção do jogo: sem ela, não existe experiência narrativa. Diferente do cinema ou da literatura, nos videogames a intervenção do usuário é "não apenas desejável, mas até mesmo exigida” (MACHADO, 2002). A estrutura gráfica presente no jogo estaria lá apenas para garantir que o sistema funcionasse, e que pudesse ser decodificado pelo interagente sem nenhuma correspondência aparente com qualquer fator do mundo externo ao jogo.

Tais premissas não excluem a existência da narrativa em um jogo. Elas apenas consideram que tal elemento, caso presente - e ele sempre vai estar, em menor ou maior função, como apontado por Juul anteriormente -, esteja subordinado à estrutura ludológica do jogo. Desse modo, segundo o autor, jogar se torna muito mais importante do que experimentar a história ou perceber como se dá a formação - o desenvolvimento ou a personalidade - de um ou outro personagem. Entretanto, é preciso considerar que, posteriormente, ao descrever suas sessões de jogo, o jogador narrará os fatos de modo que seus relatos assumam tipicamente a forma de uma história.

Embora Frasca (1999) tenha proposto uma aproximação entre as teorias, o esforço mais expressivo no sentido de aproximar tais eixos foi feito por Juul (2005). Afastando-se do viés que defendia anteriormente, o autor harmoniza os objetos de estudo de cada uma das perspectivas - a ficção e as regras -, imbricando-as em sua essência. Aproximemo-nos, neste momento, dos elementos compositores do jogo enquanto objeto: as regras e a ficção.

\section{Regras}

De acordo com Juul (2005), é necessário que assumamos que, entre outras características do jogo - como a interação entre jogadores, a 
competição ou o trabalho em grupo -, as regras configuram um dos aspectos dos quais extraímos prazer ao nele adentrar, experimentando um senso de completude ao conseguir lidar apropriadamente com um desafio por elas delimitado.

Segundo Suits (1978), os jogos apenas existem porque as regras impedem os jogadores de usar os meios mais eficientes para atingir seus objetivos. A interpretação que Juul (2005) faz da afirmação de Suits denota uma aplicação voltada para os esportes - numa competição de salto com vara, por exemplo, não se pode usar uma escada para saltar mais alto - frisando que este seria um meio mais eficiente; mas mesmo concordando parcialmente com a aplicação do que Suits aponta, Juul rejeita a interpretação de que regras seriam somente limitações - interpretação apoiada pelo trabalho de Salen e Zimmerman (2003). "Regras são 'conjuntos de instruções', e seguir tais instruções significa fazer o que as regras requerem, e não outra coisa" (SALEN e ZIMMERMAN, 2003, p. 122). Para Juul (2005), as regras de fato especificam limitações, mas elas também ajudam a criar ações específicas que possuem significado dentro do mundo do jogo, mas que, na "vida normal" (HUIZINGA, 1938), não fazem sentido. É o caso, por exemplo, de um xeque-mate em um jogo de xadrez, ou de uma peça capturada em um jogo de damas. Sendo assim, uma outra visão sobre a existência das regras é que elas ajudam a dar significação à atividade - elas produzem sentido, dando ao jogo uma estrutura minimamente previsível de como proceder.

\section{Ficção}

Embora todo jogo possua regras, muitas vezes deparamos com jogos que, além destas, projetam também um mundo ficcional ao qual estão subordinados os personagens controlados, os cenários e as ações desenvolvidas no decorrer do jogo. Segundo Juul (2005), as regras e a ficção competem pela atenção dos jogadores - sendo, então, complementares, embora assimétricas. A assimetria apontada aqui diz respeito ao fato de que se pode discursar sobre regras sem tocar no assunto da ficção, mas, apesar de os jogos - em especial os videogames, embora isso não 
signifique que sejam os únicos - se caracterizarem pela possível projeção de um mundo, é impossível lidar com a ficção nos jogos sem tocar em suas regras. Juul (2005, p. 123) aponta isso ao se referir a "mundos incoerentes" - mundos nos quais a narrativa não explica o que acontece no jogo e a única coisa que pode fazê-lo são as regras.

Na próxima seção, nos aproximaremos dos conceitos de imersão e atenção e de algumas de suas características, como tipos e níveis, relacionando-os ao conceito de círculo mágico, conforme proposto nesse trabalho.

\section{Imersão, atenção e videogames}

Jennett et al. (2008) afirmam que os processos imersivos nos videogames são distintos, por exemplo, daqueles ocorridos no cinema ou nos sistemas de realidade virtual. Fatores dos quais dependeriam a imersão, como motivação, empatia e atmosfera, ocorreriam de forma distinta nas diversas mídias aqui citadas. Todavia, além destes fatores, nosso argumento é que a atenção, conceito que tem levantado opiniões divergentes desde, pelo menos, o final do século XIX, é uma das peças fundamentais para a compreensão dos processos imersivos em todos esses meios, sobretudo nos videogames. A hipótese deste trabalho é, portanto, que os processos imersivos nos videogames estão diretamente relacionados a certos tipos de atenção por parte do jogador, e que esses processos (imersão e atenção) ocorrem de forma gradual.

\section{Imersão e atenção como experiências graduais}

Brown e Cairns (2004) definem a imersão nos videogames como uma experiência que ocorre de forma gradual. De acordo com os autores, o jogador, desde o começo de sua experiência interativa com o jogo, passará por diversos estágios, relacionados aos níveis imersivos, até que alcance o nível máximo de imersão, que seria a sensação de presença. Estes estágios são, segundo Brown e Cairns (2004), engagement (engajamento), engrossment (absorção) e total immersion (imersão total). Para 
passar de um estágio a outro, o jogador deverá superar certas barreiras, que "emergem de uma combinação de fatores humanos, informáticos e contextuais" (JENNETT et al., 2008).

O primeiro estágio, engagement, representa o menor nível de envolvimento com o jogo. As barreiras para a entrada neste nível, segundo os autores, são o acesso e o investimento de tempo. Acesso refere-se às preferências do jogador a determinado tipo de jogo. "Se eles [os jogadores] não gostarem de certo estilo de jogo, nem mesmo tentarão se engajar" (BROWN e CAIRNS, 2004). O investimento de tempo refere-se à energia despendida desde o aprendizado do jogo até o seu término, e é diretamente proporcional à imersão proporcionada pelo jogo.

Superadas essas barreiras, o jogador já estará engajado no jogo, e para chegar ao segundo estágio, engrossment (absorção), deverá superar a barreira da construção do jogo, que se refere ao seu visual, às tarefas interessantes e ao plot. Se tais características não forem aprovadas pelo jogador, ou seja, se ele perceber falhas em algum desses quesitos, dificilmente chegará ao estágio de absorção, que já prevê um maior envolvimento com o jogo.

Nesta etapa, segundo os autores, o jogador já terá dispensado bastante tempo, energia, esforço e atenção - já estará "menos ciente do seu entorno e menos ciente de si mesmo que antes" (BROWN e CAIRNS, 2004). Superada a barreira da construção do jogo, estando o jogador absorto, as próximas barreiras a serem superadas para que o jogador chegue à imersão total são a (i) empatia e a (ii) atmosfera. A primeira refere-se à sensação de estar no lugar do personagem principal, aquele controlado pelo próprio jogador; a segunda, à combinação de elementos visuais, sons e plot. Segundo Brown e Cairns (2004), tais elementos devem ser "relevantes às ações e à localização dos personagens do jogo", pois, desta forma, o jogador alocará maior atenção a esses elementos, e "quanto maior a atenção investida, mais imerso o jogador se sentirá”.

Brown e Cairns mencionam a atenção como um dos componentes dos processos imersivos nos videogames, presentes em todos esses estágios de maneira gradativa. Roger Caillois (1958), em seu clássico 
trabalho Les jeux et les hommes, já havia mencionado a importância da atenção nas atividades lúdicas. De fato, se tais atividades lúdicas compreendem processos cognitivos e sensório-motores, como apontado por Ermi e Mäyrä (2005), a atenção deve ser vista como um de seus componentes principais, já que está diretamente relacionada a esses processos. Além desses autores, outros pesquisadores em videogames confirmam uma relação próxima entre atenção e imersão e sua correspondência gradativa (JENNETT et al., 2008). Além disso, outros autores advogam que a atenção é um processo cognitivo sujeito à intensidade e a uma escala gradual (MIALET, 1999). Assim, de acordo com essa perspectiva, é possível falar em estar mais atento ou menos atento.

A seguir, serão introduzidas algumas definições e classificações a respeito da atenção, com base em alguns autores da psicologia cognitiva, no intuito de melhor relacionar atenção à imersão e seus tipos e níveis.

\section{Atenção: seletiva e limitada}

Um dos primeiros grandes pesquisadores a abordar sistematicamente a atenção, William James, tece suas primeiras definições sobre o tema em seu tratado Principles of Psychology, de 1890, no qual critica a abordagem superficial dada à atenção por parte de autores como Locke e Hume (JAMES, 1890). No entanto, somente em meados do século XX os estudos sobre a atenção ganhariam maior importância, a partir da abordagem levada a cabo pela Psicologia Cognitiva (MIALET, 1999).

Um dos denominadores comuns das várias definições de atenção repousa no fato de ser um processo (ou grupo de processos) que contribui para a seleção de uma informação em detrimento de outras. Já em James esta noção se faz presente: para o autor, atenção é “tomar posse pelo espírito, sob uma forma viva e clara, de um objeto ou corrente de pensamento entre todos aqueles que parecem se apresentar simultaneamente" (JAMES, 1890, p. 403-404). Jean-Paul Mialet (1999, p. 37), em consonância com James, afirma: "É a função seletiva da atenção, correspondente a um processo de triagem graças ao qual certas informações provenientes do ambiente ou do meio interno são analisadas 
e percebidas, enquanto outras são ignoradas. Esta atividade de triagem representa o aspecto mais característico da atenção". De acordo com Cohen (2003), esta seleção é uma necessidade própria da limitação do cérebro humano de processar informações.

Outra noção bastante difundida entre os estudos sobre a atenção é a de que dispomos de uma quantidade "limitada" de atenção para "gastar" (JAMES, 1890; MIALET, 1999; PARASURAMAN, 2000); por isso mesmo a atenção prevê um processo seletivo per se (não é possível estar atento a tudo ao mesmo tempo). Do que resulta uma outra proposição: que a atenção depende de uma intenção do sujeito, de uma escolha; não seria, como pressupunha Locke e Hume, simples fruto da experiência, algo dado a priori (JAMES, 1890; MIALET, 1999, p. 16).

Raja Parasuraman expande o conceito de seleção e o recoloca como um dos componentes da atenção, ao lado da vigilância e do controle. Segundo o autor, a seleção se faz necessária devido às limitações de processamento e computação do cérebro humano. Em suas palavras, "[s]em tal seletividade, os organismos seriam mal-equipados para agir coerentemente face às competitivas e distrativas fontes de estímulo no ambiente" (PARASURAMAN, 2000, p. 7). Ainda de acordo com o autor, todos esses componentes da atenção (seleção, vigilância e controle) têm o intuito de servir a "tarefas direcionadas a metas" (PARASURAMAN, 2000), o que implica compreender a atenção como uma "ferramenta" a serviço de uma intencionalidade, uma noção já bastante cara a James, segundo o qual a atenção nos permite melhor "perceber, conceber, distinguir e memorizar" (JAMES, 1890).

\section{Tipos de atenção}

Outro denominador comum está no fato de diversos autores tratarem a atenção como um processo que se dá de formas diferenciadas, implicando assim em diferentes tipos ou modalidades de atenção. Devido à complexidade e pluralidade de realizar tal taxonomia (MIALET, 1999) e a fim de melhor compreender as diferentes formas de atenção e suas relações com os processos imersivos dos videogames, adotar-se-á, neste 
trabalho, a proposição de Parasuraman, também compartilhada por outros autores da Psicologia Cognitiva (COHEN, 2003), que compreende a atenção através de três funções fundamentais: seleção, vigilância e controle.

\section{Modalidades imersivas e atencionais nos videogames}

Como colocado anteriormente, de acordo com Juul (2005), videogames são formados basicamente por dois componentes: regras e ficção. Durante o gameplay $y^{3}$, haverá momentos em que o elemento "regras" estará atuando em primeiro plano, enquanto a "ficção" (narrativa) ficará num estado de "suspensão"; e momentos em que a "ficção" (narrativa) estará atuando em primeiro plano, enquanto o componente "regras" entrará no estado de suspensão. Em cada um desses momentos, um tipo específico de atenção - seletiva ou sustentada - estaria atuando.

Desse modo, a partir de proposições de outros autores (ERMI e MÄYRÄ, 2005; JENNETT et al., 2008), existiriam pelo menos dois tipos/modalidades de imersão durante o gameplay, os quais estariam diretamente relacionados ao componente em primeiro plano em determinado momento do jogo - "regras" ou "ficção". Chamaremos, aqui, estes diferentes tipos de imersão de (i) imersão operacional e (ii) imersão narrativa. Além disso, acreditamos que estes tipos de imersão estão relacionados aos modos de atenção assumidos pelo jogador em cada um desses momentos - atenção seletiva e atenção sustentada, respectivamente.

\section{Atenção seletiva}

A atenção seletiva é aquela que contribui para a realização de tarefas específicas, num curto espaço de tempo. É o momento em que ocorre a filtragem de informações sensoriais, provenientes do ambiente, para que apenas as informações pertinentes à realização da tarefa sejam

\footnotetext{
${ }^{3}$ No contexto dos videogames, gameplay refere-se à própria experiência interativa entre jogador e jogo.
} 
percebidas e processadas, visando, assim, desde uma "melhora da eficiência cognitiva correspondente" a uma "otimização no tratamento da informação" (MIALET, 1999).

Acreditamos que durante o gameplay, este tipo de atenção é ativado quando o componente regras está em primeiro plano; por exemplo, quando o jogador é interpelado por um obstáculo ou desafio a ser superado. Neste momento, toda a sua atenção é voltada àquele desafio, diminuindo, por consequência, a atenção à narrativa e ao ambiente "macro" ao seu redor - tanto no jogo quanto no ambiente físico no qual o próprio jogador está localizado.

Assim, a atenção seletiva entra em ação de modo a reunir as informações mais importantes em prol da realização do objetivo ou superação do desafio. Neste momento, o jogador estará envolvido (imerso) no jogo, a partir da solução do desafio que se lhe mostra. Estas informações podem referir-se tanto a uma "camada" sensório-motora quanto a uma “camada” cognitiva. Nas palavras de Ermi e Mäyrä (2005), “[o]s desafios do gameplay parecem estar relacionados a dois diferentes domínios: habilidades sensório-motoras (...) e desafios cognitivos".

Em relação à camada sensório-motora, as informações referem-se aos diversos elementos da interface do jogo que o jogador deverá apreender, e ainda à combinação de teclas ou botões que o jogador deverá pressionar em determinado momento, para suceder ao objetivo/desafio. Quando, por exemplo, em God of War (SCE Studios Santa Mônica, 2005), Kratos entra em um recinto e se vê face a face com um boss, o jogador se vê diante de uma situação em que a atenção seletiva entra em ação, através de seus filtros sensório-motores: para atingir os golpes mais poderosos, visando seu objetivo - derrotar o boss de forma eficiente - o jogador deverá constantemente avaliar seu nível de energia, o nível de energia de seus adversários, a quantidade de poderes especiais que tem disponível, sua localização no espaço virtual do jogo etc.; essas informações estão presentes na interface do jogo (informações sensórias). Além disso, deverá estar constantemente avaliando que combinações e sequências de botões pressionar e hastes do joystick mover (e em que direção) em um dado momento (informações motoras). 
A camada cognitiva refere-se às informações solicitadas na solução de puzzles ou desafios que demandam maior formulação mental (e menos sensorial) por parte do jogador. Aqui, estas informações servirão ao pensamento estratégico e lógico. Ao solucionar um puzzle, toda a sua atenção será direcionada a esta tarefa. Os processos cognitivos devem automaticamente filtrar as informações sensório-motoras que não sejam úteis à realização da tarefa.

Assim, essas duas camadas de informação (sensório-motora e cognitiva) compreendem as informações solicitadas pela atenção seletiva, operação cognitiva que entra em ação no que chamamos de imersão operacional.

\section{Atenção sustentada}

A atenção sustentada - ou vigilância - é aquela que serve à manutenção de objetivos ao longo do tempo. Esta, de acordo com Parasuraman (2000), não ocorre em paralelo à atenção seletiva e se relaciona ao estado de espera. Acreditamos que ao longo do gameplay, esta modalidade de atenção é ativada quando o componente ficção está em primeiro plano, ou seja, quando o jogador (e seu personagem) está seguindo o curso narrativo do jogo - por exemplo, ao explorar o mundo virtual do jogo, quando nenhum elemento específico (puzzle ou desafio) requer sua atenção.

Neste período, o jogador tem a possibilidade de monitorar várias fontes de informação sem perda de eficiência (PARASURAMAN, 2000), como, por exemplo, seu ambiente, o que inclui detalhes do cenário e dos objetos do jogo, diálogos, e ainda sua trilha sonora: elementos que concorrem para a ambientação e o envolvimento do jogador no universo do jogo e, ainda, para o desenvolvimento de sua narrativa. A atenção sustentada só é possível de ser mantida enquanto não ocorrer o aparecimento de um alvo crítico (novo puzzle ou desafio a ser superado), quando a atenção seletiva retornará ao primeiro plano. Além disso, a atenção sustentada remonta ao estado de espera ou de alerta e, por isso mesmo, relaciona-se à vigilância. 
No intuito de manter o compasso do gameplay, a construção do jogo deverá se encarregar do equilíbrio entre momentos de ação (puzzles ou desafios) e momentos de narrativa (de espera) (INCE, 2006). De fato, é justamente nos momentos de espera, nos quais a atenção sustentada se faz mais presente, que o jogo poderá explorar a imersão através dos elementos narrativos, não excluindo, aqui, os apelos sensoriais (visuais e sonoros), colocando o jogador na expectativa do próximo momento crítico, deixando-o assim envolvido no game flow (INCE, 2006). Desse modo, durante um gameplay completo, ou seja, desde que o jogador inicia o jogo até o seu término, o que se vê é uma constante alternância entre momentos de imersão operacional e imersão narrativa, assim como uma alternância entre atenção seletiva e a atenção sustentada. Isto é o que chamamos de modos alternados de imersão e atenção do gameplay.

\section{Controle e círculo mágico}

Relacionamos aqui o terceiro componente da atenção, o controle, ao conceito de círculo mágico como elemento mediador entre jogador e jogo, conforme anteriormente proposto. O controle, ou função executiva, é o responsável pela distribuição da quantidade de atenção à cada tarefa realizada em determinado momento, de acordo com sua prioridade (COHEN, 2003).

Durante o gameplay, o controle estará em constante operacionalização, gerenciando a quantidade de atenção dispensada ao jogo e àquela dispensada aos elementos externos a este. Como afirma Juul (2005), a ação de jogar um jogo é composta tanto pela relação entre o jogador e o jogo quanto pela relação entre o jogador e o mundo real. De fato, o jogador está situado em um espaço físico externo ao jogo, sendo atingido por uma quantidade enorme de estímulos sensoriais e cognitivos a todo instante, devendo, assim, evitar esses estímulos para se manter imerso no jogo (BROWN e CAIRNS, 2004).

Ao mesmo tempo, ele pode ter de responder a alguma dessas solicitações externas, como, por exemplo, uma chamada telefônica ou o convite 
de sua mãe para sentar-se à mesa e jantar. Eis uma questão central para a compreensão do círculo mágico como um elemento mediador: se o jogador responder a alguma dessas solicitações externas, ele sairá do círculo mágico e voltará à sua vida cotidiana?

Acreditamos que não. Que, como um elemento mediador, o círculo mágico, através do controle, direciona parte da atenção do jogador àquela solicitação, mantendo ainda uma parcela direcionada ao jogo. Em outras palavras: apesar de o jogador, neste momento, se relacionar a um elemento externo, ele não deixará o círculo mágico, mas estará em uma posição mais externa da escala imersiva. Aqui retomamos a ideia de que imersão e atenção estão direta e gradualmente relacionadas e propomos que ambas são responsáveis pela "posição" do jogador na escala gradativa do círculo mágico. Resumindo nossa proposição, o círculo mágico, através do controle atencional, gerencia a relação entre jogador e jogo em uma escala gradativa entre menos imerso e mais imerso no jogo (e, respectivamente, mais ou menos "presente" na vida real, "fora" do jogo).

\section{Considerações finais}

Nossa intenção com este trabalho foi a de oferecer uma revisão bibliográfica minuciosa a respeito do círculo mágico, que incorpora não apenas seu entendimento clássico - especialmente aquele oferecido por Huizinga (1938), Salen e Zimmerman (2003) e Juul (2005) -, e acrescentar uma compreensão mais ampla que harmonize as ideias clássicas com algumas ideias da Psicologia Cognitiva. Não é nosso objetivo refutar os padrões estabelecidos, utilizados pelos estudos em videogames, ou sugerir que eles necessitam ser reescritos, mas apenas oferecer uma compreensão diferente, que objetiva melhorar a interseção entre os game studies e as áreas da cibercultura e da Psicologia Cognitiva.

Deste modo, questionamos o conceito de círculo mágico, como defendido por diversos autores, com suas bordas "binárias" (dentro-fora do círculo mágico). No nosso entendimento, o círculo mágico funcionaria muito mais no nível cognitivo, proporcionando novos significados ao contexto no qual o jogador está inserido - a relação entre jogador e 
espaço, tempo, objetos e fluxo de informação digital, no que diz respeito ao jogo; ele não funcionaria na direção de uma dicotomia excludente dentro-fora, mas através de gradientes que levam a uma maior ou menor imersão no jogo.

\section{Referências}

AARSETH, E. Cybertext. Baltimore: Londres: The Johns Hopkins University Press, 1997.

BROWN, E.; CAIRNS, P. A Grounded Investigation of Game Immersion. In: ACM CONFERENCE ON HUMAN FACTORS IN COMPUTING SYSTEMS (CHI) 2004. Anais... Viena: ACM Press, 2004. p. 1.297-1.300.

CAILLOIS, R. Man, Play and Games. Chicago: University of Illinois Press, 1958.

COHEN, A. Selective Attention. In: ENCYCLOPEDIA OF COGNITIVE SCIENCE. [s.l.]: Nature Publishing Group, 2003. Disponível em: http://atar.mscc.huji.ac.il/ acohenlab/files/ency_final.pdf. Acesso em: 10 jul. 2014.

ERMI, L.; MÄYRÄ, F. Fundamental Components of the Gameplay Experience: Analysing Immersion. In: DIGRA 2005 CONFERENCE. Anais... Vancouver: DiGRA, 16-20 jun. 2005.

FRASCA, G. Ludology meets Narratology. Similitude and differences between (video) games and narrative. Ludology.org., 1999. Disponível em: http://www.ludology.org/articles/ludology.htm. Acesso em: 30 jul. 2015.

HUIZINGA, J. Homo Ludens. Boston: Beacon Press, 1938.

INCE, S. Writing for Video Games. Londres: A\&C Black, 2006.

JAMES, W. Principles of Psychology. [s.1.], 1890. Disponível em: http://psychclassics. yorku.ca/James/Principles/index.htm. Acesso em: 30 jul. 2015.

JENNETT, C.; COX, A.; CAIRNS, P. Being 'In the Game'. In: THE PHILOSOPHY OF COMPUTER GAMES CONFERENCE 2008. Anais... Potsdam: Potsdam University Press, 8-10 maio 2008.

JUUL, J. Half-Real. Cambridge, Mass.: The MIT Press, 2005.

JUUL, J. The Magic Circle and the Puzzle Piece. In: THE PHILOSOPHY OF COMPUTER GAMES CONFERENCE 2008. Anais... Potsdam: Potsdam University Press, 8-10 maio 2008.

MACHADO, A. Regimes de Imersão e Modos de Agenciamento. In: XXV CONGRESSO ANUAL EM CIÊNCIA DA COMUNICAÇÃO. Anais... Salvador, 2002.

MIALET, J-P. L'Attention. Paris: Presses Universitaires de France, 1999.

MURRAY, J. Hamlet on the Holodeck. Cambridge, Mass.: The MIT Press, 1997. 
PARASURAMAN, R. (Org.). The Attentive Brain. Cambridge, Mass.: The MIT Press, 2000.

SALEN, K.; ZIMMERMAN, E. Rules of Play. Cambridge, Mass.: The MIT Press, 2003. SUITS, B. The Grasshopper. Toronto: University of Toronto Press, 1978.

TURKLE, S. Always-on/Always on you. The Tethered Self. In: KATZ, J. (Org.). Handbook of Mobile Communication Studies. Cambridge, Mass.: The MIT Press, 2008.

YEE, N. The Proteus Paradox: How Online Games and Virtual Worlds Change Us - And How They Don't. Londres: Yale University Press, 2014.

\section{Sobre os autores}

Emmanoel Ferreira - Doutor em Comunicação e Cultura pela Escola de Comunicação da Universidade Federal do Rio de Janeiro (UFRJ). Professor do Departamento de Estudos Culturais e Mídia e do Programa de Pós-graduação em Mídia e Cotidiano, ambos ligados ao Instituto de Arte e Comunicação Social da Universidade Federal Fluminense (UFF).

Thiago Falcão - Doutor em Comunicação e Cultura Contemporânea pela Universidade Federal da Bahia (UFBA), com estágio sanduíche financiado pela Capes na McGill University, no Canadá. Professor colaborador do Programa de Pós-graduação em Comunicação da Universidade Anhembi Morumbi e professor dos cursos de graduação em Rádio e TV, na Universidade Anhembi Morumbi, e Estudos de Mídia, na Universidade Federal Fluminense.

Data de submissão: 08/09/2015

Data de aceite: 02/02/2016 